\title{
Efeito de biorregulador na germinação e no vigor de sementes de soja
}

\author{
Lia Mara Moterle ${ }^{1}$, Renato Frederico dos Santos ${ }^{2}$, Carlos Alberto Scapim ${ }^{3}$, Alessandro de Lucca e Braccini ${ }^{3}$, \\ Carlos Moacir Bonato ${ }^{3}$, Thiago Conrado
}

\section{RESUMO}

Os biorreguladores vegetais são substâncias que podem incrementar o crescimento e o desenvolvimento vegetal e estimular a divisão celular, podendo interferir na germinação das sementes. Assim, neste trabalho objetivou-se avaliar a qualidade fisiológica de sementes sob a ação de biorregulador. Utilizaram-se sementes de nove cultivares comerciais de soja (Glycine max (L.) Merrill) e três concentrações (400; 500 e $600 \mathrm{~mL} 100 \mathrm{~kg}^{-1}$ de sementes) do biorregulador Stimulate ${ }^{\circledR}$, além da testemunha, constituída de tratamento com água destilada. Testes de germinação e de vigor foram realizados em sementes, observando-se a percentagem de germinação (primeira contagem e contagem final), percentagem de plântulas normais fortes, velocidade de germinação, comprimento da raiz primária e da parte aérea, bem como a biomassa da matéria seca das plântulas. O delineamento experimental foi inteiramente casualizado, com quatro tratamentos e quatro ou cinco repetições, dependendo do teste. Doses crescentes de biorregulador não influenciaram a germinação e a biomassa da mtéria seca das sementes; entretanto, podem aumentar a velocidade de germinação, dependendo do cultivar.

Palavras-chave: Glycine max, regulador de crescimento, qualidade fisiológica.

\section{ABSTRACT}

\section{Effect of plant growth regulator on germination and vigor of soybean seeds}

Plant growth regulators can enhance growth and development of plants and induce cell division. They can also interfere in seed germination. The objective of this study was to evaluate the physiological quality of seeds treated with a plant growth regulator. Seeds of nine soybean (Glycine max (L.) Merrill) commercial cultivars were treated with

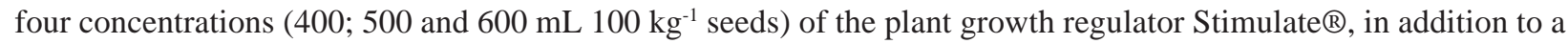
control treated with distilled water. Tests of seed germination and vigor were carried out: it was calculated the germination percentage (first counting and final counting), percentage of normal seedlings; and speed of germination, length of the primary root and the aerial part and dry weight of seedlings were recorded. The experiment was arranged in a completely randomized design with four treatments and four or five repetitions depending on the test. Increasing doses of the plant growth regulator did not influence the germination and the dry weight of the seeds, however, they can increase the speed of germination depending on the cultivar.

Key words: Glycine max, plant growth regulator, physiological quality .

Recebido para publicação em 04/02/2009 aprovado em 30/08/2011

'Engenheira-Agrônoma, Doutora. Departamento de Agronomia, Faculdade Integrado de Campo Mourão Rodovia BR 158, km 207, 87300-970, Campo Mourão, Paraná, Brasil. *Imoterle@ hotmail.com (*autor para correspondência)

${ }^{2}$ Engenheiro-Agrônomo, Mestrando do PGA. Departamento de Agronomia, Universidade Estadual de Maringá (UEM), Av. Colombo, 5790, 87020-900, Maringá, Paraná, Brasil. agronomorenato@hotmail.com

${ }^{3}$ Engenheiro-Agrônomo, Doutor. Departamento de Agronomia, Universidade Estadual de Maringá (UEM), Av. Colombo, 5790, 87020-900, Maringá, Paraná, Brasil. cascapim @ uem.br, albraccini@uol.br, cmbonato@uem.br

${ }^{4}$ Engenheiro-Agrônomo, Mestre. Doutorando do Departamento de Biologia, Universidade Federal de Lavras (UFLA), Centro, C. Postal 3037, 37200-000, Lavras, Minas Gerais, Brasil.tconrado28@hotmail.com 


\section{INTRODUÇÃO}

Nas últimas décadas, a área cultivada com soja tem aumentado significativamente. Nesse contexto, o gerenciamento eficiente e o uso de tecnologias visando a reduzir custos e a aumentar a produtividade passam a ter especial importância para os produtores participarem em mercados cada vez mais globalizados e competitivos.

Uma das etapas mais importantes na produção da soja é a obtenção de sementes de elevada qualidade, que possam ser economicamente utilizadas pelos agricultores no estabelecimento de suas lavouras (Rocha et al., 1996). A garantia de melhor desempenho de determinada cultura depende, fundamentalmente, da qualidade das sementes (Motta et al., 2000), caracterizada pela germinação e vigor. $\mathrm{O}$ vigor caracteriza-se pela habilidade de determinado lote de sementes estabelecer plântulas normais em condições de campo.

Atualmente, o uso de reguladores vegetais nas culturas do arroz, milho, soja, feijão e algodão tem potencializado o aumento da produtividade, embora sua utilização ainda não seja prática rotineira entre os produtores de culturas de alto nível tecnológico, como a soja. Os biorreguladores vegetais são substâncias sintetizadas que, aplicadas exogenamente, possuem ações similares à dos grupos de fitormônios conhecidos (Vieira \& Castro, 2002), os quais promovem, inibem ou modificam processos fisiológicos e morfológicos do vegetal (Castro \& Vieira, 2001). De acordo com Raven et al. (2007), os hormônios são capazes de regular o crescimento e o desenvolvimento, em parte pelo fato de produzirem efeitos amplificados. Uma única molécula de hormônio pode desencadear uma cascata de eventos metabólicos, repercutindo em mudanças no desenvolvimento intracelular. Segundo Salisbury \& Ross (1992), um determinado fitormônio pode expressar sua ação no mesmo local de síntese ou longe dele, em diferentes fases do desenvolvimento.

As auxinas são responsáveis pelo crescimento das plantas, agindo diretamente nos mecanismos de expansão e diferenciação celular (Vieira \& Monteiro, 2002). As citocininas estão diretamente relacionadas com o processo de divisão celular e em processos de desenvolvimento vegetativos e reprodutivos, na germinação de sementes e na quebra de dormência de gemas (Raven et al., 2007; Vieira \& Monteiro, 2002). As giberelinas possuem a função de promover o crescimento caulinar, estimulando o alongamento e a divisão celular (Salisbury \& Ross, 1992), além de serem dos principais fitormônios atuantes no processo de germinação das sementes (Raven et al, 2007; Taiz \& Zeiger, 2004).

Segundo Vieira \& Monteiro (2002), as substâncias reguladoras podem ser combinadas com outras substân- cias, para agirem durante o processo germinativo das sementes e, também, em eventos pós-germinativos, como a mobilização de reservas, crescimento e desenvolvimento do embrião.

Vieira \& Castro (2001), avaliando a ação de bioestimulante na germinação de sementes, vigor de plântulas e produtividade de soja observaram aumentos na quantidade de plântulas normais, na massa da matéria seca de plântulas, na produção de grãos e de massa da matéria seca de grãos por planta.

Aragão et al. (2001) verificaram efeito favorável do fitorregulador $\mathrm{GA}_{3}$ na velocidade e na percentagem de germinação, com consequente reflexo na qualidade das plântulas de milho.

Desse modo, neste trabalho objetivou-se avaliar a germinação e o vigor de sementes de cultivares comerciais de soja sob o efeito de biorregulador.

\section{MATERIAL E MÉTODOS}

O experimento foi conduzido no Laboratório de Tecnologia de Sementes, do Núcleo de Pesquisas Aplicadas à Agricultura (NUPAGRI), do Departamento de Ciências Agrárias da Universidade Estadual de Maringá-PR. Utilizaram-se sementes de nove cultivares comerciais de soja: CD-202, CD-208, CD-215, CD 216, BRS-184, BRS-214, CD214RR, BRS-244RR e BRS-245RR.

As sementes foram tratadas com o biorregulador Stimulate ${ }^{\circledR}$, nas dosagens de 400; 500 e $600 \mathrm{~mL} 100 \mathrm{~kg}^{-1}$ de sementes, sendo a testemunha constituída de tratamento com água destilada.

O biorregulador, constituído de cinetina $(0,009 \%)$, ácido giberélico $(0,005 \%)$ e ácido indol-butírico $(0,005 \%)$ foi aplicado diretamente sobre as sementes acondicionadas em sacos plásticos com capacidade de $2,0 \mathrm{~kg}$, com auxílio de pipeta graduada, agitando-as vigorosamente durante um minuto para melhor homogeneização.

Avaliou-se a qualidade fisiológica por meio dos seguintes testes e determinações:

Teste de germinação (\%) - foi realizado com quatro subamostras de 50 sementes cada, sendo o volume de água equivalente a três vezes a massa do papel seco (Brasil, 2009). Os rolos confeccionados foram colocados em germinador do tipo Mangelsdorf, a temperatura constante de $25 \pm 2{ }^{\circ} \mathrm{C}$. A percentagem de plântulas normais, conforme as Regras para Análise de Sementes (Brasil, 2009), foi analisada no oitavo dia do início do experimento.

Velocidade de germinação (dias) - determinada durante o teste de germinação, constou da contagem diária do número de sementes que apresentaram a protrusão da radícula. A velocidade de germinação foi calculada segundo o procedimento descrito por Edmond e Drapala (1958), empregando-se a seguinte fórmula: 


$$
V E=\frac{N_{1} G_{1}+N_{2} G_{2}+\ldots+N_{n} G_{n}}{G_{1}+G_{2}+\ldots+G_{n}}, \text { em que: }
$$

$\mathrm{VE}=$ velocidade de emergência (dias);

$\mathrm{G}=$ número de plântulas emergidas em cada contagem;

$\mathrm{N}$ = número de dias da semeadura a cada contagem.

Outras avaliações de vigor foram também utilizadas, dentre elas a primeira contagem, a classificação do vigor das plântulas, o comprimento da raiz primária e da parte aérea e a biomassa da matéria seca das plântulas.

A primeira contagem de germinação foi realizada no quinto dia após a montagem do teste, adotando-se a mesma metodologia descrita anteriormente para o teste de germinação (Brasil, 2009). As plântulas normais obtidas foram classificadas, para avaliação do vigor, em plântulas normais fortes e fracas, de acordo com Nakagawa (1999).

Para a avaliação do comprimento das plântulas, foram utilizadas cinco repetições de 20 sementes para cada tratamento, colocadas para germinar nas mesmas condições do teste de germinação. As sementes foram distribuídas no sentido longitudinal das folhas, com o hilo voltado para a extremidade inferior do substrato. Os rolos confeccionados foram colocados em pé, no germinador, à temperatura de $25 \pm 2{ }^{\circ} \mathrm{C}$. O comprimento das plântulas (raiz primária e parte aérea) consideradas normais foi avaliado, no sétimo dia, com auxílio de régua milimetrada; os resultados foram expressos em cm/plântula (Nakagawa, 1999).

A obtenção da biomassa da matéria seca média ( $\mathrm{g} /$ plântula) das plântulas foi realizada após a avaliação do comprimento. As plântulas normais foram colocadas em sacos de papel devidamente identificadas e secas, em estufa, com circulação de ar forçada, ajustada a $80 \pm 2{ }^{\circ} \mathrm{C}$, por período de $24 \mathrm{~h}$ e, então, realizada a pesagem em balança analítica $(0,001$ g) (Nakagawa, 1999).

Adotou-se o delineamento experimental inteiramente casualizado (D.I.C.), em esquema fatorial $9 \times 4$, sendo: 9 (cultivares) x 3 (concentrações), além da testemunha, com quatro repetições. Para as variáveis comprimento de plântulas e biomassa da matéria seca, foram utilizadas cinco repetições. $\mathrm{O}$ efeito dos tratamentos foi verificado, pelo teste $\mathrm{F}$, com nível de significância de 5\% de probabilidade. Após a análise de variância preliminar, as variáveis quantitativas foram analisadas pela regressão polinomial.

\section{RESULTADOS E DISCUSSÃO}

As doses aplicadas não influenciaram significativamente $(\mathrm{P}<0,05)$ a percentagem de germinação dos cultivares testados (Tabela 1). Estes resultados contrariam os encontrados por Vieira \& Castro (2001), que obtiveram efeitos do bioestimulante sobre a germinação de sementes de soja (cv. IAC-8-2), quando verifi- caram que a concentração de $3,5 \mathrm{~mL}$ de bioestimulante por $0,5 \mathrm{~kg}^{-1}$ de sementes proporcionou o número máximo de plântulas normais, com aumento de 51,9\% em relação ao controle.

Vieira et al. (1999), também observaram incremento na germinação de sementes de soja tratadas com bioestimulante, principalmente por causa das reduções significativas na quantidade de plântulas anormais. No entanto, os resultados encontrados no presente estudo concordam com os resultados obtidos por Vieira et al. (2001) e Vieira (2005), em que o bioestimulante não afetou significativamente a qualidade fisiológica de sementes de soja e algodão, respectivamente. Alleoni et al. (2000), em ensaios com feijão, também não observaram diferença no "stand" inicial com o tratamento de sementes com biorregulador.

Na cultura da soja, Leite et al. (2003) concluíram que a aplicação conjunta de giberelina e citocinina tendeu a diminuir os efeitos da giberelina, visto que o número de plântulas emergidas aos 15 dias foi reduzido com o tratamento de sementes, resultados estes compatíveis com os apresentados neste estudo, em que o biorregulador apresenta em sua formulação ambos os hormônios. Deve-se, entretanto, ressaltar que, mais do que a concentração dos fitormônios, a relação entre eles pode determinar muitas vezes seus efeitos e eventos fisiológicos. Além disso, os fatores abióticos podem influenciar sobremaneira a ação dos fitormônios nas sementes e a aplicação dos fitormônios na superfície das sementes não garante a sua absorção, pelo menos em sua totalidade (Buchanan et al., 2001).

A quantidade de fitormônios absorvida depende fundamentalmente da superfície de contato da semente e da quantidade de água e da concentração da solução, contendo os biorreguladores, absorvida pelas sementes (Buchanan et al., 2001). Assim, a menor absorção do biorregulador pode ter comprometido sua eficiência na variável germinação, aqui considerada.

O fato de os fitormônios não afetarem, neste caso, a percentagem de germinação, mas afetarem as outras variáveis, pode ser explicado pela sensibilidade dos tecidos, pelo estádio de desenvolvimento da soja e também pelo efeito cumulativo dos fitormônios. Quando a planta se estabelece no solo, aumenta sua superfície de contato e pode absorver, com maior eficiência, as substâncias diluídas na solução do solo.

Em relação à primeira contagem de germinação (Tabela 1), observa-se influência das diferentes doses do biorregulador nos cultivares CD 202, CD 215 e BRS 214 (Figura 1). O ajuste da equação de regressão quadrática ocorreu para os cultivares CD 202 e CD 215, sendo 65,77 e $44,83 \%$ a resposta máxima da primeira contagem nas doses de 328,2 e $266,7 \mathrm{~mL}$ de biorregulador por $100 \mathrm{~kg}$ de sementes, respectivamente. 


\begin{tabular}{|c|c|c|c|c|c|c|c|}
\hline Cultivares & Germinação & Primeira contagem da germinação & Plântulas normais fortes & Velocidade de germinação & Comprimento da parte aérea & $\begin{array}{c}\text { Comprimento da raiz } \\
\text { primária }\end{array}$ & $\begin{array}{l}\text { Biomassa } \\
\text { m. seca }\end{array}$ \\
\hline CD 202 & $\hat{Y}=\bar{Y}=88,75$ & $\begin{array}{c}\hat{Y}=48,04+0,108062 x-0,000164 x^{2} \\
R^{2}=0,99 \\
\text { Ponto de máximo: } 328,2 \mathrm{~mL} \\
\text { Resposta máxima: } 65,77 \%\end{array}$ & $\hat{Y}=\bar{Y}=79,00$ & $\hat{Y}=\bar{Y}=2,14$ & $\hat{Y}=\bar{Y}=9,65$ & $\hat{Y}=\bar{Y}=12,30$ & $\hat{Y}=\bar{Y}=0,04429$ \\
\hline CD 208 & $\hat{Y}=\bar{Y}=90,75$ & $\hat{Y}=\bar{Y}=67,50$ & $\begin{array}{c}\hat{Y}=76,28+0,014578 x \\
r^{2}=0,83\end{array}$ & $\hat{Y}=\bar{Y}=2,06$ & $\hat{Y}=\bar{Y}=10,80$ & $\hat{Y}=\bar{Y}=17,01$ & $\hat{Y}=\bar{Y}=0,04346$ \\
\hline CD 215 & $\hat{Y}=\bar{Y}=70,00$ & $\begin{array}{c}\widehat{Y}=37,46+0,055271 x-0,000103 x^{2} \\
R^{2}=0,97 \\
\text { Ponto de máximo: } 266,7 \mathrm{~mL} \\
\text { Resposta máxima: } 44,83 \%\end{array}$ & $\hat{Y}=\bar{Y}=55,25$ & $\hat{Y}=\bar{Y}=2,28$ & $\hat{Y}=\bar{Y}=9,51$ & $\hat{Y}=\bar{Y}=12,79$ & $\hat{Y}=\bar{Y}=0,04210$ \\
\hline CD 216 & $\hat{Y}=\bar{Y}=90,12$ & $\hat{Y}=\bar{Y}=59,75$ & $\hat{Y}=\bar{Y}=78,00$ & $\begin{array}{c}\widehat{Y}=2,20+0,000485 x-0,000001 x^{2} \\
R^{2}=0,87 \\
\text { Ponto de máximo: } 194,1 \mathrm{~mL} \\
\text { Resposta máxima: } 2,24 \text { dias }\end{array}$ & $\begin{array}{c}\hat{Y}=10,28+0,003519 x \\
r^{2}=0,75\end{array}$ & $\hat{Y}=\bar{Y}=17,51$ & $\hat{Y}=\bar{Y}=0,04527$ \\
\hline BRS 184 & $\hat{Y}=\bar{Y}=73,00$ & $\hat{Y}=\bar{Y}=41,37$ & $\hat{Y}=\bar{Y}=61,75$ & $\hat{Y}=\bar{Y}=2,15$ & $\begin{array}{c}\widehat{Y}=8,53+0,019310 x-0,000033 x^{2} \\
R^{2}=0,97 \\
\text { Ponto de máximo: } 291,1 \mathrm{~mL} \\
\text { Resposta máxima: } 11,34 \mathrm{~cm}\end{array}$ & $\hat{Y}=\bar{Y}=15,43$ & $\hat{Y}=\bar{Y}=0,04567$ \\
\hline BRS 214 & $\hat{Y}=\bar{Y}=92,87$ & $\begin{array}{c}\hat{Y}=52,13+0,0483133 x \\
r^{2}=0,99\end{array}$ & $\begin{array}{c}\hat{Y}=72,79+0,032228 x \\
r^{2}=0,91\end{array}$ & $\begin{array}{c}\hat{Y}=2,32-0,0004536 x \\
r^{2}=0,93\end{array}$ & $\begin{array}{c}\hat{Y}=9,84+0,012805 x-0,000018 x^{2} \\
R^{2}=0,90 \\
\text { Ponto de máximo: } 355,2 \mathrm{~mL} \\
\text { Resposta máxima: } 12,11 \mathrm{~cm}\end{array}$ & $\hat{Y}=\bar{Y}=15,01$ & $\hat{Y}=\bar{Y}=0,04429$ \\
\hline CD 214RR & $\hat{Y}=\bar{Y}=86,66$ & $\hat{Y}=\bar{Y}=65,75$ & $\begin{array}{c}\hat{Y}=72,27+0,019277 x \\
r^{2}=0,90\end{array}$ & $\hat{Y}=\bar{Y}=2,08$ & $\hat{Y}=\bar{Y}=11,04$ & $\begin{array}{c}\hat{Y}=11,64+0,008104 x \\
r^{2}=0,93\end{array}$ & $\hat{Y}=\bar{Y}=0,03825$ \\
\hline BRS 244RR & $\hat{Y}=\bar{Y}=98,62$ & $\hat{Y}=\bar{Y}=75,25$ & $\begin{array}{c}\hat{Y}=79,72+0,028072 x \\
r^{2}=0,86\end{array}$ & $\hat{Y}=\bar{Y}=2,03$ & $\hat{Y}=\bar{Y}=9,12$ & $\hat{Y}=\bar{Y}=17,62$ & $\hat{Y}=\bar{Y}=0,04945$ \\
\hline BRS 245RR & $\hat{Y}=\bar{Y}=76,25$ & $\hat{Y}=\bar{Y}=51,00$ & $\hat{Y}=\bar{Y}=62,12$ & $\hat{Y}=\bar{Y}=2,12$ & $\hat{Y}=\bar{Y}=9,35$ & $\begin{array}{c}\widehat{Y}=14,51+0,004529 x \\
r^{2}=0,78\end{array}$ & $\hat{Y}=\bar{Y}=0,04617$ \\
\hline
\end{tabular}


A primeira contagem de germinação das sementes do cultivar BRS 214 apresentou resposta linear, com coeficiente angular positivo em relação às doses de bioestimulante, ou seja, a percentagem de germinação obtida na primeira contagem aumentou proporcionalmente à dose do biorregulador aplicada (Figura 1). Neste caso, sugerese que os fitormônios presentes no biorregulador promoveram o aumento do vigor obtido na primeira contagem de germinação, fruto de suas ações na divisão e alongamento celular, enquanto os menores valores de germinação, a partir dos pontos de máxima dos cultivares CD 202 e CD 215, sugerem efeito inibitório dos fitormônios, em especial, no alongamento e divisão celular. A absorção do biorregulador pode ter ocorrido de modo díspar, entre os cultivares, o que pode explicar em parte os resultados observados neste experimento. Como mencionado anteriormente, a absorção pode variar entre diferentes cultivares. Em alguns, as sementes podem absorver menos fitormônios e, ou, apresentar menor sensibilidade a estas substâncias. Entretanto, há necessidade de mais estudos para comprovar estas hipóteses.

Em relação às plântulas normais fortes (Tabela 1), os cultivares CD 208, BRS214, CD 214RR e BRS 244RR apresentaram comportamento linear crescente e proporcional à dose do biorregulador (Figura 2), diferindo dos resultados obtidos por Vieira (2005), em sementes de algodão tratadas com bioestimulante. Este autor não verificou aumento significativo na percentagem de plântulas normais fortes. Segundo Vieira \& Castro (2004), os bioestimulantes agem de forma eficiente e eficaz sobre diversos processos fisiológicos fundamentais, como no vigor inicial de plântulas e na produção de compostos orgânicos. Aparentemente, os fitormônios estimularam a degradação das reservas e sua mobilização para o crescimento inicial das plântulas, refletindo, assim, no aumento do vigor das plântulas, observado pela maior percentagem de plântulas normais fortes.

A velocidade de germinação das sementes dos cultivares CD 216 e BRS 214 também sofreu influência da aplicação do biorregulador (Figura 3). Para o cultivar CD 216, a resposta máxima de velocidade de germinação foi de 2,24 dias, na dose de 194,1 mL do biorregulador por $100 \mathrm{~kg}$ de sementes (Tabela 1). Comportamento contrário foi observado para o cultivar BRS 214 (Tabela 1).

Os resultados para o cultivar CD 216 estão de acordo com Prado Neto et al. (2007), os quais, utilizando Stimulate $^{\circledR}$ a $10 \mathrm{~mL} \mathrm{~L}^{-1}$, observaram aumento significativo do índice de velocidade de germinação de sementes de jenipapeiro, indicando efeito positivo destas substâncias no desempenho das variáveis anteriormente citadas. Provavelmente, para o cultivar CD 216 doses menos elevadas, como 194,1 mL de biorregulador por $100 \mathrm{~kg}$ de sementes, proporcionaram diminuição na velocidade de germinação, devida à menor concentração de hormônios. No caso do cultivar BRS 214, o aumento na velocidade de germinação pode ser explicado pela maior sensitividade da membrana plasmática ao biorregulador. É provável que, para este cultivar, a adição de hormônios de maneira equilibrada faça que haja maior diferenciação e divisão celular em menor período de tempo.

A aplicação de fitormônios nas sementes de alguns cultivares pode ter efeito inibitório na velocidade de ger-

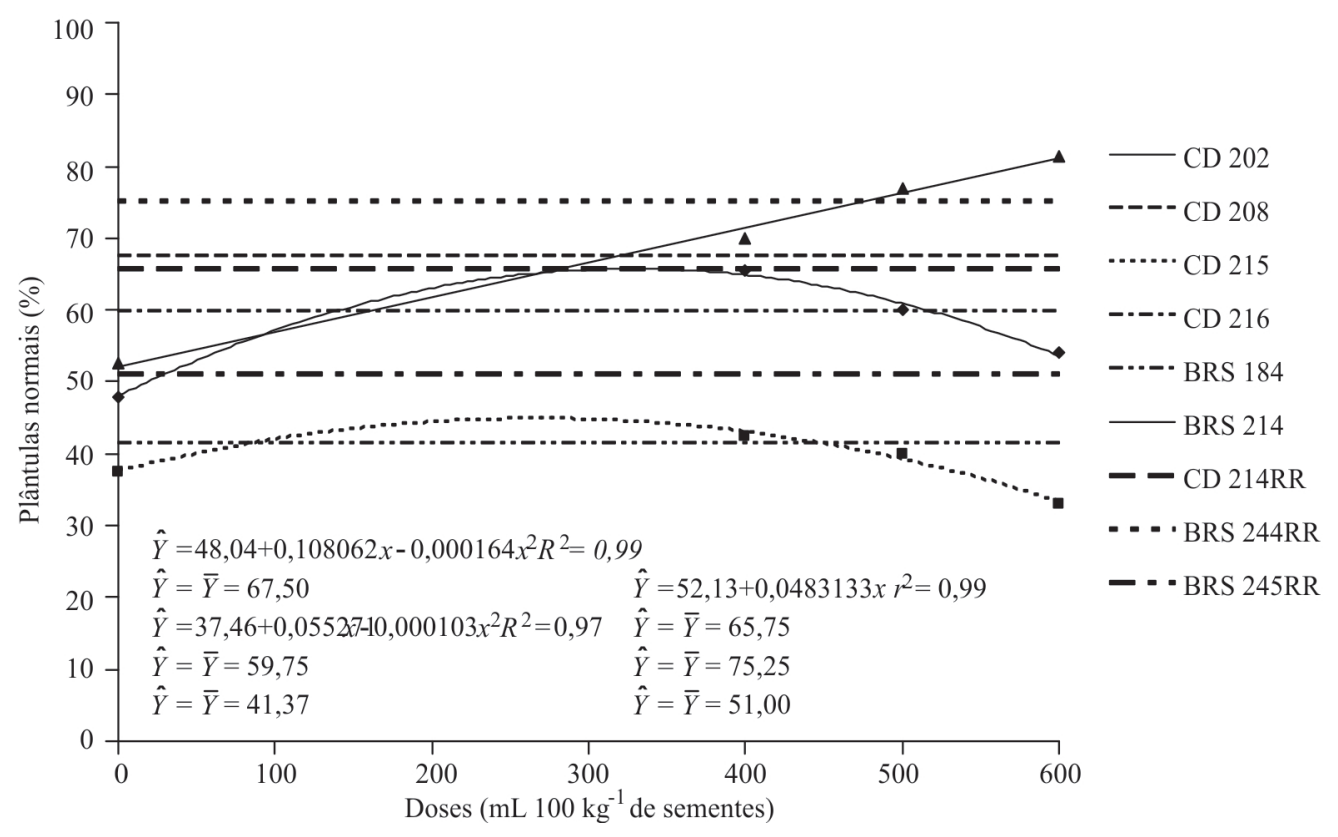

Figura 1. Percentagem de plântulas normais na primeira contagem do teste de germinação das sementes de nove cultivares de soja, de acordo com o aumento nas doses de biorregulador aplicado via sementes. 
minação, como aconteceu para alguns, neste experimento. Os fitormônios, neste caso, podem ter modulado negativamente a síntese ou expressão de algumas enzimas importantes no processo de germinação das sementes.

Para os demais cultivares, a não significância na variável velocidade de germinação deve-se, provavelmente, às diferenças morfogenéticas e, ou, taxas de absorção diferenciadas do biorregulador entre os cultivares. Barbosa (2006), avaliando o efeito da aplicação foliar de bioestimulante sobre a produção e qualidade fisiológica das sementes de três cultivares de arroz, também observou com- portamentos diferenciados, entre os cultivares, em resposta ao bioestimulante. Esse fato foi explicado por Raven et al. (2007), quando mencionaram que a resposta a um dado regulador não depende somente da sua estrutura química, mas também de como ele é reconhecido pelo tecido alvo. Observa-se que, o comprimento da parte aérea também sofreu influência do tratamento de sementes com biorregulador, dependendo do cultivar avaliado (Tabela 1). Houve aumento linear significativo no comprimento da parte aérea das plântulas do cultivar CD 216, em resposta à aplicação de doses crescentes de biorregulador

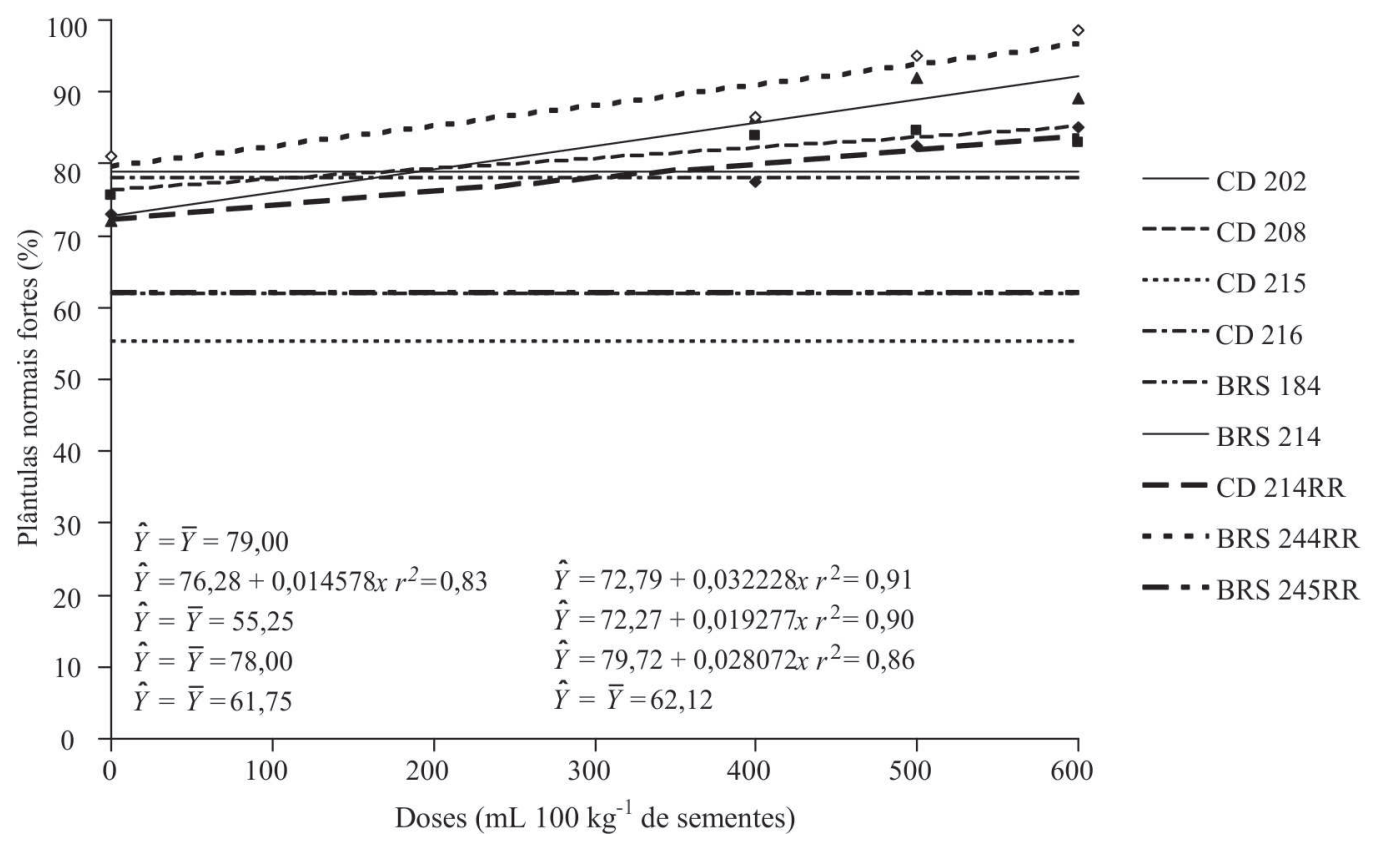

Figura 2. Percentagem de plântulas normais fortes no teste de classificação do vigor dasplântulas de nove cultivares de soja,de acordo com o aumento nas doses de biorregulador, aplicado via sementes.

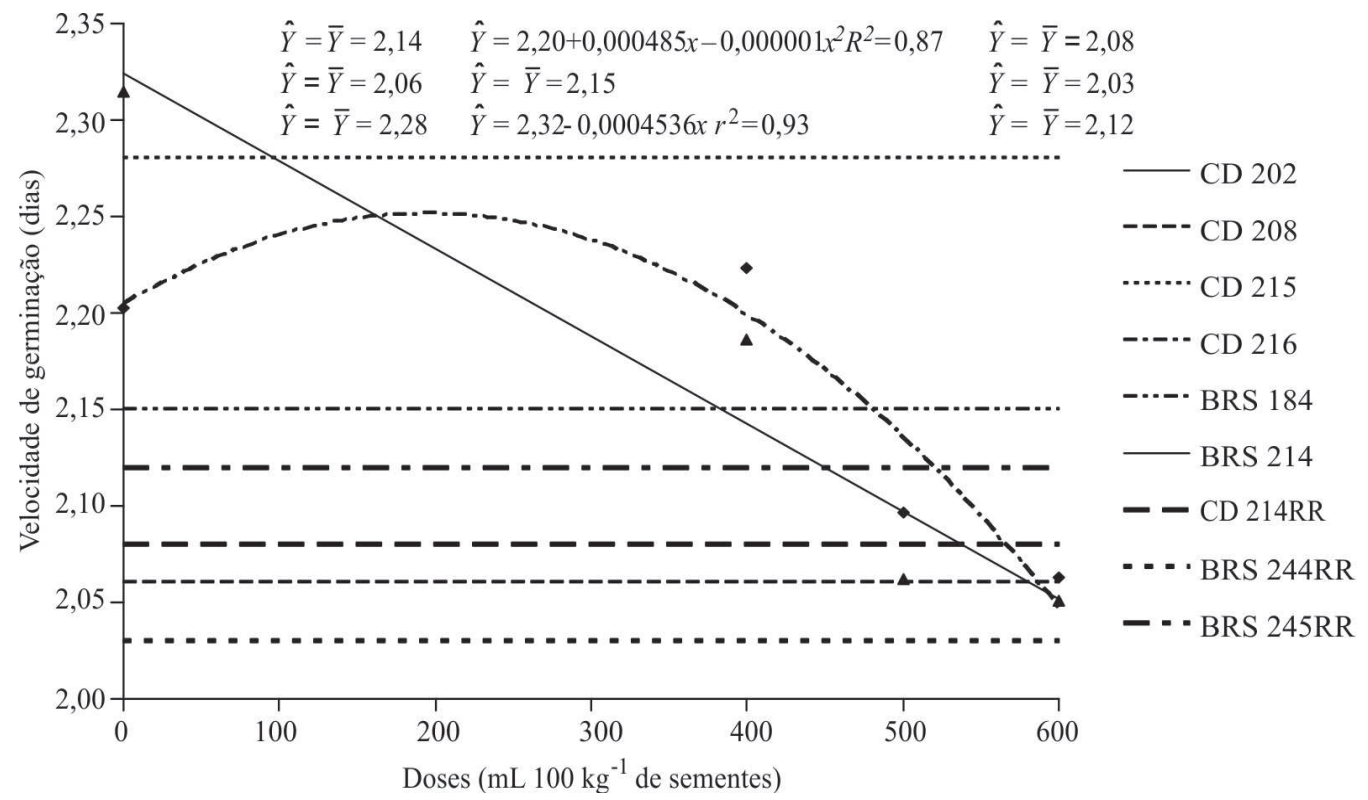

Figura 3. Velocidade de germinação de nove cultivares de soja, de acordo com o aumento nas doses de biorregulador, aplicado via sementes.

Rev. Ceres, Viçosa, v. 58, n.5, p. 651-660, set/out, 2011 
via sementes (Figura 4). De acordo com Taiz \& Zeiger (2004), as giberelinas aumentam o alongamento e a divisão celular, o que é evidenciado pelo aumento do comprimento da célula e do número de células. As giberelinas também participam do crescimento do caule, podendo reverter o nanismo. Segundo Leite et al. (2003), a giberelina também tem efeito no crescimento das plântulas. Para esses autores, quando essa substância é aplicada exogenamente em sementes, não é muito translocada para a parte aérea das plantas, e isso talvez ocorra de uma forma que seja suficiente para aumentar o hipocótilo até certo tamanho, mas não é suficiente para afetar a altura da planta. De fato, de acordo com os resultados demonstrados por Bensen et al. (1990) e Tanimoto (1990), a taxa de crescimento do hipocótilo está diretamente associada com a quantidade de $\mathrm{GA}_{3}$.

Aragão et al. (2001), utilizando tratamentos de $\mathrm{GA}_{3}$ combinado com citocinina, obtiveram aumento no comprimento de raiz primária de plântulas de milho doce. Aragão et al. (2006) observaram, em sementes tetraploides de melancia, maior crescimento de plântulas em função do uso do $\mathrm{GA}_{3}$, combinado com a escarificação e a maceração. Assim, as maiores taxas de crescimento verificadas neste estudo podem ter ocorrido em função do aumento na formação de novas células e do maior alongamento celular em resposta à giberelina.

Pode-se observar, na Tabela 1 que, o ajuste da equação de regressão ocorreu para os cultivares BRS 184 e BRS 214, em que as respostas máximas do comprimento da parte aérea, estimado pelas funções, foram 11,34 e 12,11 cm, respectivamente, nas doses 291,1 e 355,2 mL de biorregulador por $100 \mathrm{~kg}$ de sementes (Figura 4). Wang et al. (1996) observaram que doses elevadas, em torno de $0,3 \mathrm{mM}$, de giberelina e citocinina, retardaram tanto a emergência como o desenvolvimento inicial de plântulas de soja.

Em relação à auxina, Taiz \& Zeiger (2004) relataram que este hormônio provoca aumento na taxa de crescimento celular em pouco tempo. Isso ocorre pela biossíntese e ação da auxina na $\mathrm{H}^{+}$-ATPase sobre a pressão de turgor e afrouxamento bioquímico da parede celular, culminando em maior expansão celular. Para esses cultivares, provavelmente houve maior estensibilidade da parede celular, até se chegar ao máximo comprimento alcançado. A partir daí, o biorregulador pode ter provocado efeito tóxico, pela modulação positiva na biossíntese de etileno devida a sua alta concentração na planta.

Uma das possíveis explicações para a falta de resposta dos demais cultivares à aplicação de biorregulador para a característica comprimento das plântulas pode ser a diferença de sensibilidade entre os cultivares e até mesmo a interação entre os hormônios presentes no produto. Valio \& Schwabe (1978) observaram interação negativa entre $\mathrm{GA}_{3}$ e citocinina no alongamento do caule em feijoeiro, enquanto Leite et al. (2003) também verificaram que estes dois reguladores promoveram alongamento quando utilizados separadamente, mas, quando usados em conjunto, a citocinina inibiu a plena ação do $\mathrm{GA}_{3}$

No que se refere ao comprimento da raiz primária (Tabela 1), foi possível notar que, à medida que se aumentou a dose do biorregulador via sementes, houve aumento linear no comprimento da raiz primária das plântulas dos cultivares CD 214RR e BRS 245RR (Figura 5). Sementes

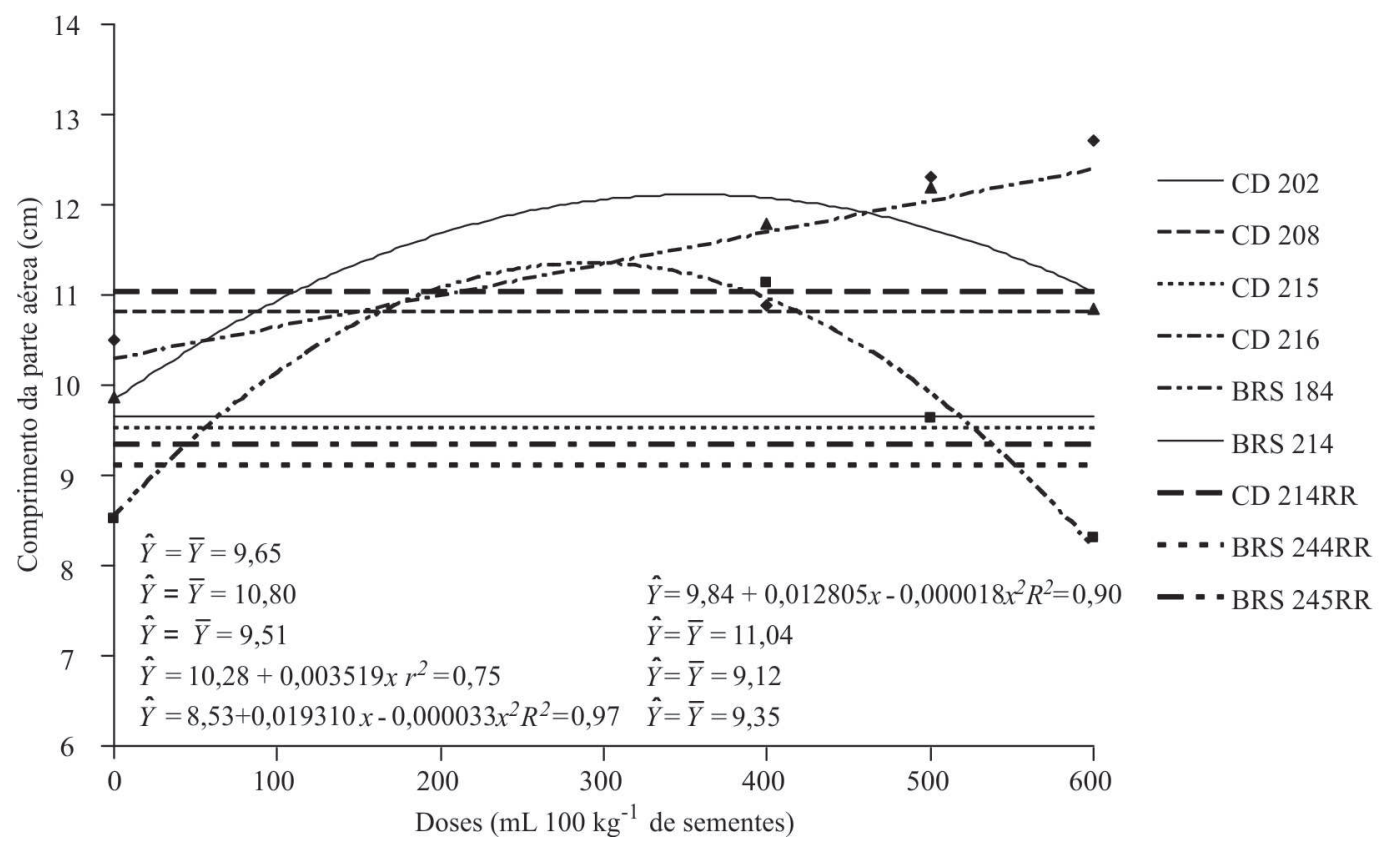

Figura 4. Comprimento da parte aérea das plântulas de nove cultivares de soja, de acordo com o aumento nas doses de biorregulador, aplicado via sementes. 
de algodão, tratadas com bioestimulante, tiveram um aumento de 45,5\% no comprimento das raízes das plântulas, utilizando-se a dose de $17,4 \mathrm{~mL}$ de Stimulate $®$ por $0,5 \mathrm{~kg}$ de sementes (Vieira, 2005). Vieira (2001), estudando a ação do Stimulate ${ }^{\circledR}$ em sementes de arroz e feijão, observou que o comprimento total dos sistemas radiculares foi superior em $37,7 \%$ para a dose de $2,3 \mathrm{~mL}$ de Stimulate ${ }^{\circledR}$ nas plantas de arroz e 19,8\% para a dose de 5,0 mL de Stimulate ${ }^{\circledR}$ por $0,5 \mathrm{Kg}$ de sementes, no feijoeiro. Rosolem (1997) também obteve efeito significativo sobre o comprimento radicular de plantas de feijoeiro, quando pulveri-

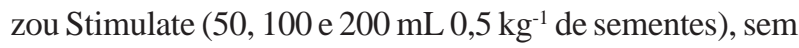
associação com os micronutrientes cobalto e molibdênio, em sementes e após a emergência das plântulas. Reghin et al. (2000), em trabalho feito com mandioquinha-salsa (Arracacia xanthorriza Bancroft), constataram efeito significativo do Stimulate $®$, no número e comprimento de raízes, indicando o bioestimulante como estimulador do crescimento e desenvolvimento radicular, podendo estar relacionado com a ação dos reguladores promotores do crescimento radicular, presentes no Stimulate.

Segundo Vieira (2005), existe relativamente pouca evidência de que tais substâncias reguladoras do crescimento funcionem como uma chave regulatória na emergência da raiz primária. Entretanto, no presente estudo, o bioestimulante pode ter influenciado positivamente nas reações metabólicas e, de certa forma, estimulou o crescimento das radículas dos cultivares CD 214RR e BRS 245RR, principalmente nas doses mais elevadas (Figura 5). De acordo com Coll et al. (1992), a radícula, geralmente, é o primeiro ponto de crescimento formado pela semente, além de ser sítio de síntese e de liberação de hormônios vegetais, como a auxina, à qual é muito sensível em baixas concentrações, e, segundo Vieira (2005), o crescimento e o desenvolvimento mais rápido e pronunciado do que o do hipocótilo, provavelmente, é o que lhe confere a facilidade de interagir com o produto.

Possivelmente, para os cultivares que não responderam aos tratamentos, a auxina presente no biorregulador utilizado pode ter influenciado na formação das raízes secundárias, que são drenos preferenciais, em detrimento do crescimento da raiz primária.

Hartmann \& Kester (1983) afirmaram que o uso de reguladores de crescimento para induzir o enraizamento difere em sua ação de acordo com a espécie e com o cultivar. Enquanto algumas espécies enraízam muito melhor com a sua aplicação, outras respondem fracamente ou ainda adversamente.

Os aumentos no comprimento da raiz primária e na parte aérea de determinados cultivares podem confirmar algum efeito do biorregulador como estimulador da divisão celular, diferenciação e alongamento das células, podendo também, aumentar a absorção e a utilização de água e dos nutrientes pelas plantas (Stoller do Brasil, 1998). No entanto, como pôde ser observado neste trabalho, a maioria dos cultivares não respondeu significativamente à aplicação de biorregulador via sementes, tanto para o comprimento da parte aérea como para o da raiz primária das plântulas, necessitando-se de mais informações a respeito da utilização e do efeito do produto.

A produção de biomassa da matéria seca não foi influenciada pela aplicação crescente do biorregulador (Tabe-

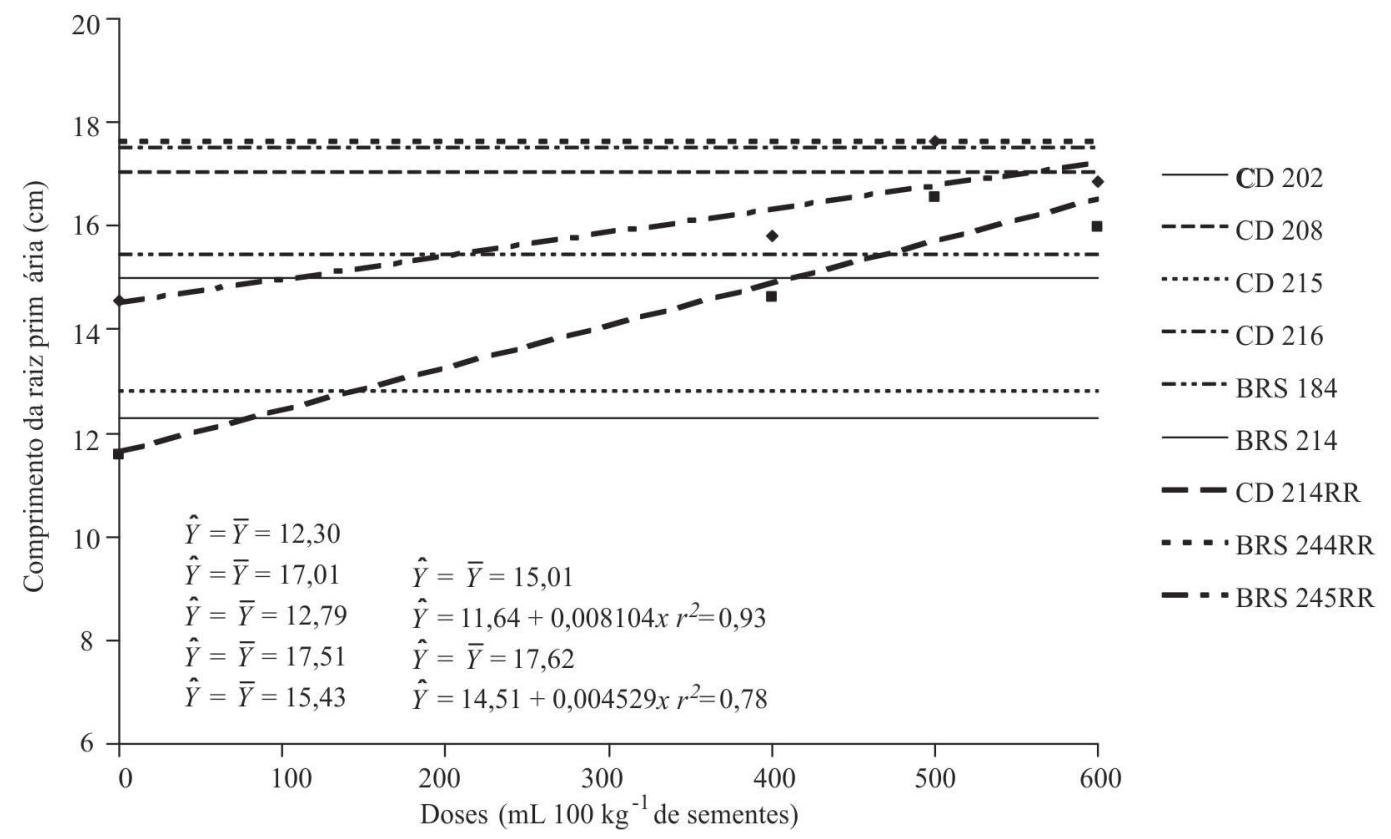

Figura 5. Comprimento da raiz primária das plântulas de nove cultivares de soja, de acordo com o aumento nas doses de biorregulador, aplicado via sementes.

Rev. Ceres, Viçosa, v. 58, n.5, p. 651-660, set/out, 2011 
la 1). Resultados obtidos por Vieira \& Castro (2001) demonstram comportamento contrário. A concentração de $4,1 \mathrm{~mL}$ do produto em soja incrementou $55,3 \%$ nos valores de massa da matéria seca de plântulas, enquanto Lima et al. (1993) verificaram que a massa da matéria seca da parte radicular de arroz aumentou quando tratadas as sementes com ácido giberélico. Trabalhando com variáveis da cultura da soja, Leite et al. (2003) observaram que a adição de giberelinas e citocininas exógenas não contribuiu para o aumento da matéria seca da raiz e que a associação de giberelina e citocinina tendeu a diminuir os efeitos da giberelina. Da mesma maneira, Valio \& Schwabe (1978) observaram interação negativa entre a $\mathrm{GA}_{3}$ e cinetina.

$\mathrm{O}$ fato de que muitos cultivares não responderam positivamente à aplicação de doses crescentes de biorregulador para as características avaliadas pode estar associado a mecanismos metabólicos e, ou, morfogenéticos diferenciados entre os cultivares, os quais requerem eficiência nesses mecanismos durante a fase inicial de desenvolvimento. As diferenças na superfície de contato das sementes e na sensitividade pelas membranas plasmáticas podem ter comprometido a eficiência do biorregulador. Também pode ter havido desequilíbrio hormonal pela aplicação do produto. Segundo Wang et al. (1996), o uso de diferentes cultivares nos trabalhos que envolvem biorreguladores pode ser responsável pela discrepância entre os resultados. Isso foi demonstrado por Nalawadi et al. (1973), que utilizaram 18 diferentes cultivares e observaram aumento na germinação, em alguns e falta de resposta em outros, sob tratamento semelhante ou até mesmo em concentrações muito mais elevadas, 0,2 a $1 \mathrm{mg}$ $\mathrm{GA}_{3}$ por semente, como as utilizadas por Riedell et al. (1985). Diante disso, são necessários novos estudos com diferentes cultivares, testando-se diferentes dosagens de biorregulador aplicado via sementes.

\section{CONCLUSÃO}

Doses crescentes de biorregulador não influenciaram a germinação e a biomassa da matéria seca das sementes, entretanto podem aumentar o vigor, dependendo do cultivar.

\section{REFERENCIAS}

Alleoni B, Bosqueiro M \& Rossi M (2000) Efeito dos reguladores vegetais de Stimulate no desenvolvimento e produtividade do feijoeiro (Phaseolus vulgaris L.). Publicatio UEPG, 6:23-35.

Aragão CA, Deon MD, Queiróz MA \& Dantas BF (2006) Germinação e vigor de sementes de melancia com diferentes ploidias submetidas a tratamentos pré-germinativos. Revista Brasileira de Sementes, 28:82-86.

Aragão CA, Lima MWP, Morais OM, Ono EO, Boaro CSF, Rodrigues JD, Nakagawa J \& Cavariani C. (2001) Fitorreguladores na germinação de sementes e no vigor de plântulas de milho super doce. Revista Brasileira de Sementes, 23:62-67.
Barbosa GT (2006) Efeito da aplicação de doses de bioestimulante sobre a produção e qualidade fisiológica das sementes de três cultivares de arroz. Dissertação de Mestrado. Universidade Estadual Paulista, Ilha Solteira. 40p.

Bensen RJ, Beall FD, Mullet JE \& Morgan PW (1990) Detection of endogenous gibberellins and their relationship to hypocotyl elongation in soybean seedlings. Plant Physiology, 94:77-84.

Brasil. Ministério da Agricultura, e Pecuária e Abastecimento. Regras para análise de sementes. Ministério da Agricultura, Pecuária e Abastecimento. Secretaria de Defesa Agropecuária. Brasília, DF: Mapa/ACS, 2009. 395 p.

Buchanan BB, Gruissem W, Jones RL (2000) Biochemistry \& Molelular Biology of Plants. American Society of Plant Physiologists. Rockville, Maryland. 1367p.

Castro PRC \& Vieira EL (2001) Aplicação de reguladores vegetais na agricultura tropical. Guaíba, Agropecuária. 132p.

Coll JB, Rodrigo GN, Garcia BS \& Tamés RS (1992) Fisiologia vegetal. Madrid, Piramide. 662p.

Edmond JB \& Drapala WJ (1958) The effects of temperature, sand and soil, and acetone on germination of okra seeds. Proceedings of American Society of Horticultural Science, 71:428-434.

Hartmann HT \& Kester DE (1983) Plant propagation: principles and practices, 4 ed. New Jersey, Prentice-Hall. 727p.

Leite VM, Roselem CA \& Rodrigues JD (2003) Gibberellin and cytokinin effects on soybean growth. Scientia Agricola, 60:537541.

Lima GPP, Rodrigues JD \& Brasil OG (1993) Efeito de giberelina em variáveis bioquímicas durante o crescimento inicial de arroz (Oryza sativa L.) cultivado in vitro. I- teores de açúcares redutores e proteínas. Científica, 21:265-274.

Motta IS, Braccini ALB, Scapim CA, Gonçalves ACA, Braccini MCL \& Ávila MR (2000) Qualidade fisiológica de sementes de soja provenientes de diferentes épocas de semeadura. Revista Brasileira de Sementes, 22:257-267.

Nakagawa J (1999) Teste de vigor baseado no desempenho das plântulas. In: Krzyzamowski FC, Vieira RD \& França-Neto JB (Eds.) Vigor de sementes: conceito e testes. Londrina, Abrates. p.1-24.

Nalawadi UG, Prithvi R \& Krishnamurthy K (1973) Improvement in the seed germination of soybean varieties by pre-soaking treatments. Indian Journal of Agricultural Sciences, 43:546550 .

Prado Neto M, Dantas ACVL, Vieira EL \& Almeida VO (2007) Germinação de sementes de jenipapeiro submetidas à préembebição em regulador e estimulante vegetal. Ciência e Agrotecmologia, 31:693-698.

Raven PH, Evert RF, Eichhorn SE (2007) Biologia vegetal. 7a ed. Rio de Janeiro, Guanabara Koogan. 856p.

Reghin MY, Otto RF \& Silva JBC (2000) “Stimulate® Mo" e proteção com tecido "não tecido" no pré-enraizamento de mudas de mandioquinha-salsa. Horticultura Brasileira, 18:53-56.

Riedell WE, Khoo U \& Inglett GE (1985) Effects of bioregulators on soybean leaf structure and chlorophyll retention. Plant Growth Regulation, 1:204-212.

Rocha VS, Oliveira AB, Sediyama T, Gomes JLL, Sediyama CS \& Pereira MG (1996) A qualidade da semente de soja. Viçosa, UFV. 76p. (Boletim 188)

Rosolem CA (1997) Stimulate em tratamento de sementes de feijão. Botucatu, UNESP. 5p. (Relatório Técnico)

Salisbury FB \& Ross C (1992) Plant physiology. 4 ed. California, Wadsworth. 682p.

Rev. Ceres, Viçosa, v. 58, n.5, p. 651-660, set/out, 2011 
Stoller do Brasil (1998) Stimulate Mo em hortaliças: Informativo técnico. Cosmópolis, Stoller do Brasil. 1p.

Taiz L \& Zeiger E (2004) Fisiologia Vegetal. 3 ed. Porto Alegre, Artmed. 559p.

Tanimoto E (1990) Gibberelin requirement for the normal growth of roots. In: Takahashi $\mathrm{N}$ et al. (Eds.) Gibberelins. New York, Springer-Verlag. p.229-240.

Valio IFM \& Schwabe WW (1978) Correlative growth in seedling of Phaseolus vulgaris L.: Inhibition of stem growth by the primary leaves. Annals of Botany, 42:263-268.

Vieira EL (2001) Ação de bioestimulante na germinação de sementes, vigor de plântulas, crescimento radicular e produtividade de soja (Glycine $\max$ (L.) Merrill), feijoeiro (Phaseolus vulgaris L.) e arroz (Oryza sativa L.). Tese de Doutorado. Escola Superior de Agricultura Luiz de Queiroz, Piracicaba. 122p.

Vieira EL (2005) Stimulate 10 X na germinação de sementes, vigor de plântulas e crescimento inicial de plantas de algodoeiro. In: V Congresso Brasileiro de Algodão, Salvador. Anais. Embrapa Algodão. p.163-163.

Vieira EL \& Castro PRC (2001) Ação de bioestimulante na germinação de sementes, vigor de plântulas, crescimento radicular e produtividade de soja. Revista Brasileira de Sementes, 23:222228.
Vieira EL \& Castro PRC (2002) Ação de estimulante no desenvolvimento inicial de plantas de algodoeiro (Gossypium hirsutum L.). Piracicaba, USP. Dept ${ }^{\circ}$. Ciências Biológicas. 3p.

Vieira EL \& Castro PRC (2004) Ação de bioestimulante na cultura da soja (Glycine max (L.) Merrill). Cosmópolis, Stoller do Brasil. $47 \mathrm{p}$.

Vieira EL, Castro PRC \& Monteiro CA (1999) Efeito de Stimulate na germinação e vigor de sementes de soja. In: I Congresso Brasileiro de Soja, Londrina. Resumos. Embrapa Soja. p.361361.

Vieira EL, Martins MC, Spinola MCM \& Castro PRC (2001) Estudos preliminares da ação de Stimulate e inoculante na qualidade fisiológica de sementes e no desenvolvimento inicial do sistema radicular de plantas de Glycine max L. (Merrill). In: XII Congresso Brasileiro de Sementes, Curitiba. Resumos, Informativo ABRATES. p.65-65.

Vieira EL \& Monteiro CA (2002) Hormônios vegetais. In: Introdução à fisiologia vegetal. Maringá, Eduem. p.79-104.

Wang Q, Zhang F \& Smith D (1996) Aplicattion of $\mathrm{GA}_{3}$ and kinetin to improve corn and soybean seedling emergence at low temperature. Environmental and Experimental Botany, 36:377383. 